\title{
A Note on Translations, Terminology, and the Limits of Language
}

The nineteenth century was a time of immense change in the Americas. National borders were drawn and redrawn; old and new categories of race, ethnicity, and caste clashed with and changed one another; new legal categories and social modes of belonging emerged and old ones evolved; and individuals contemplated and debated their identity at the individual, national, and international levels. Language could not always keep up. It is therefore difficult to use stable ethnic, racial, national, geographic, and regional descriptors for individuals and communities in the Americas during the nineteenth century because these could, and did, change rather quickly and depended to a great extent on context. This is in part what Forgotten Futures, Colonized Pasts is about: how national, racial, ethnic, communal, and individual terms of self-identification changed over time and in different contexts within the Americas. There are inherent limitations to language when it comes to naming entities that are in nearly constant flux, but I will attempt to be clear and precise about my use of these descriptors. Whenever possible, I strive to use the terms that the individuals and communities I am studying used for selfidentification. Usually, these are connected to regional rather than national affiliations, but they also simultaneously carry cultural and sometimes racial or ethnic dimensions. Thus as each chapter of my book focuses on different regions and communities, I use regional terms employed by the authors for self-identification in their writing, such as Tejano, Yucateco, Californio, and Nuevomexicano; I use these terms as the authors use them, even when it is problematic or exclusionary. I include more detailed discussions of specific terminology in the notes to each chapter. 
For similar reasons, I use the term America (and American) to refer to all the Americas, not just the United States of America. Americano was a term employed frequently in the nineteenth century by people from throughout the Americas, not just from the United States. I use the term U.S. American to refer to people from the United States so as to discursively detach American from belonging solely to the United States. Although use of U.S. American might at first appear somewhat awkward, my hope is that with more frequent use it will become less so.

I have chosen to maintain spelling, accent marks, antiquated grammatical features, lexical choices, and so on as they appear in the original texts. I do this in part to reflect the tone and feeling of the texts and because I want to convey the language and voices of the writers themselves as much as possible. This language can at times appear archaic or, at other times, convoluted, extravagant, and opaque. I have chosen not to modernize the language because I want readers to engage with this sometimes alienating aspect of the language in part as an attempt to recognize that the language of these texts, in great measure, is not the language of the masses but rather that of a community of letrados - the lettered elites, as Ángel Rama explains in La ciudad letrada, who are also the ruling classes. I include all quotations in the original language in which they were written and have provided English translations following the original Spanish; these are purposefully literal translations, again as part of my attempt to draw readers' attention to the (sometimes coded and oblique) language of the original. All translations are my own unless otherwise noted.

I have chosen to use the masculine ending for gender-variable terms such as Hispano, Chicano, and so on for several reasons. First, I find the constant use of the split variation (e.g., Chicana/o, Latino/a) grammatically and syntactically awkward. Second, although I considered using the feminine and masculine versions interchangeably (as some do with gender-specific singular pronouns in English), I find the feminine endings potentially confusing, as the feminine variation may inadvertently and erroneously convey the idea that I am speaking about a woman or a group of women (e.g., Chicana or Chicanas). Lastly, the writers I study in this book almost invariably use the masculine variation when referring to their own communities, thereby reflecting the patriarchal gender norms of their times and places. I ask readers to see my use of the masculine form not as an unquestioning reinforcement of gender inequality but as an attempt to acknowledge and represent, through the use of the normative masculine, the thorough marginalization of women - a marginalization that was so ingrained in society, even in language itself, that it was rarely even recognized as such in the nineteenth century. I follow the same logic that I use in maintaining the racial and cultural terms of self-identification employed by my writers, even when highly problematic, so as to not erase the violence inherent in naming. For example, while it is true that most Mexicans were biologically 
racially mixed by the nineteenth century and therefore could be described as mestizo (in our present-day use of the term), elites rarely self-identified as mestizo. Lastly, although I recognize the socially and culturally constructed nature of race and ethnicity, for sake of reading fluidity, I do not place racial or ethnic terms within quotation marks unless I desire to specifically emphasize the constructed or self-reflective nature of the term being used. For the same reasons, I also avoid excessive use of quotation marks with words like civilization, modern/modernization, barbaric/barbarism, progress, and so on, although I once again ask readers to consider these terms as discursive constructs that nonetheless have immense meaning and power for the writers I analyze and their audiences.

Language is tricky, and the words we use to describe people are especially fraught with cultural baggage. It seems that in choosing any word, one immediately privileges some and excludes others, often unintentionally. My hope is that the terms I use in this book are understood less as static terms and more as markers for larger ideas that cannot always be accurately described through the limited language at my disposal. I ask readers to understand my use of these terms, similar to my decision to use masculine noun and adjective forms, as a recognition-not an endorsement-of how these terms and categories were used for both empowerment and disempowerment in the nineteenth century. These terms offer a critical reflection on the ways in which hierarchies of inclusion and exclusion permeate and reproduce themselves within society at every level, including through language itself. 

Forgotten Futures, Colonized Pasts 
